\title{
Visible Garden Biodiversity Leads to an Increase in Noticing Nature, Which in Turn Leads to an Increase in Nature Connectedness
}

\author{
Iain Hamlin \& Miles Richardson
}

\begin{abstract}
A strong connection to nature promotes behaviours that help conserve the natural world. However, it is likely that this relationship is reciprocal, with the pathways to nature connectedness including care for nature through pro-nature conservation behaviours and sensory contact with nature. Pro-conservation behaviours vary in terms of how much visible biodiversity, and therefore contact with nature, they produce. It is likely that conservation behaviours that support higher visible biodiversity will result in more sensory contact with nature and therefore greater levels of nature connectedness. The present research investigates the relationship between garden-focussed pro-nature conservation behaviour, noticing nature and nature connectedness using data from Natural England's People and Nature Survey in the UK, a large national survey that includes items to measure noticing nature, nature connectedness, and pro-nature conservation behaviours. Results suggest that undertaking garden-based pro-nature conservation behaviours that enhance visible biodiversity leads to an increase in noticing nature, which in turn leads to an increase in nature connectedness. These results point to a relatively simple way to boost human connection to nature: boost and engage people with visible biodiversity.
\end{abstract}

Keywords: pro-nature conservation behaviour, nature connectedness, noticing nature, garden biodiversity 